\title{
Plasma Catecholamines and Carbohydrate Metabolism in Patients with Acute Myocardial Infarction
}

\author{
Niels Juel Christensen and J $\varnothing$ rgen Videbaek \\ From The Second Clinic of Internal Medicine and the Department of Cardiology, \\ Kommunehospitalet, Arhus, Denmark
}

A в S T R A C T Blood glucose, glucose tolerance, serum insulin, free fatty acids in serum, plasma noradrenaline, and plasma adrenaline were measured in 10 patients with acute myocardial infarction (AMI) as well as in healthy subjects. Both noradrenaline and adrenaline in plasma were elevated in patients with AMI, the level being fairly constant in the individual patients and dependent on their degree of illness.

In the fasting state, blood glucose, serum insulin, and free fatty acids were elevated in patients with AMI. Plasma noradrenaline showed a highly significant correlation with the fasting blood glucose concentration, but not with serum insulin or free fatty acids. The concentration of free fatty acids in serum could be predicted only if both plasma noradrenaline and the basal insulin concentration were known.

Intravenous glucose tolerance was / reduced in patients with AMI, especially in patients with high plasma noradrenaline and a low initial rise in insulin. There was a significant negative correlation between the initial rise in insulin expressed in percentage of the basal insulin concentration and the plasma noradrenaline level. The statistical effects of serum insulin and plasma noradrenaline on the glucose tolerance could not be separated from each other. The decline in free fatty acids after intravenous injection of glucose showed a negative correlation with plasma noradrenaline and a positive correlation with the initial rise in insulin.

Plasma adrenaline did not correlate with any of the metabolic parameters mentioned above.

The plasma noradrenaline concentration was elevated to such a degree in patients with AMI that the observed changes in metabolism might have been caused directly by the circulating noradrenaline.

During the glucose tolerance tests, the effect of noradrenaline was probably carried out indirectly via a suppression of insulin secretion. It is conceivable that

Received for publication 3 January 1974 and in revised form 5 March 1974. any effect of plasma noradrenaline on the basal insulin secretion was neutralized by the fasting hyperglycemia.

\section{INTRODUCTION}

It is generally accepted that the activity of the adrenergic system is increased in patients with acute myocardial infarction (AMI). ${ }^{1}$ Plasma catecholamine concentration is elevated and in the individual patient the level is fairly constant during the first 2 days after admission to hospital. The level may vary considerably in different patients and is dependent upon their degree of illness $(1,2)$.

Most patients with AMI show a diabetes-like change in metabolism. Glucose tolerance is impaired (3-7) and free fatty acids are raised $(5,8,9)$. Less consistent results have been reported for plasma insulin $(4,5,7,10)$. An increased adrenergic activity is often assumed to be at least partially responsible for the altered metabolic state.

Very little information is available about the relationship between the degree of augmented adrenergic activity and blood glucose concentration, serum insulin, and free fatty acids (FFA) in patients with AMI. The best way of estimating adrenergic activity is probably by measuring the concentration of noradrenaline and adrenaline in plasma. Previously it had been very difficult or impossible to obtain reliable measurements of circulating catecholamines by the various fluorimetric methods. However, this problem has been overcome by the introduction of a sensitive and precise double-isotope derivative technique for the determination of noradrenaline and adrenaline (11-13).

In the present study plasma noradrenaline and plasma adrenaline were measured in 10 patients with AMI,

${ }^{1}$ Abbreviations used in this paper: AMI, acute myocardial infarction; Na-Ad, plasma noradrenaline at admission to hospital; Na-Fa, plasma noradrenaline after overnight fast; $\mathrm{Na}-\mathrm{Gt}$, plasma noradrenaline during the glucose tolerance test. 
shortly after their admission to hospital, after overnight fasting, and after intravenous injection of glucose. The main purpose of the study was to elucidate to what extent augmented adrenergic activity is responsible for the metabolic changes observed in patients with AMI, and especially to study the relationship between circulating catecholamines and the concentration of FFA in serum, as well as catecholamine-insulin interrelationships.

\section{METHODS}

Subjects. 10 patients, admitted to a coronary care unit within $12 \mathrm{~h}$ after onset of precordial pain, were studied. All of them had unequivocal signs of recent transmural myocardial infarction in electrocardiogram and enzyme analyses. Four patients had anterior wall infarctions, one an anteroseptal, and five posterior wall infarctions. None of the patients had known diabetes mellitus or hypertension and none were taking drugs known to influence the sympathetic nervous system.

After admission to hospital, all patients received an injection of an analgesic drug. The dose was repeated later on if necessary. Digitalization was started in three patients. Shortly after their admission to hospital, two patients received lignocaine as intravenous bolus injection due to multiple ventricular ectopic beats. No patients received intravenous glucose infusion or heparin before the glucose tolerance test.

A degree of illness index in the individual patient was calculated as described previously (1). In addition the degree of illness was also evaluated with the coronary prognostic index described by Norris, Brandt, Caughey, Lee, and Scott (14).

Four patients were reexamined 3 mo after their discharge from hospital.

Plasma catecholamine concentrations in control subjects admitted to a coronary care unit with precordial pain but without evidence of cardiovascular disease have been presented elsewhere (1). However, an additional five normal subjects were examined with special reference to their metabolic responses.

Procedure. Venous blood was collected from the superior vena cava via an indwelling catheter while the patients rested in the recumbent position. Samples were obtained shortly after the patients were admitted to hospital, after overnight fasting, and during an intravenous glucose tolerance test.

$25 \mathrm{~g}$ of glucose was injected intravenously over $4 \mathrm{~min}$. Blood was collected at 2 -min intervals, calculated from the midpoint of the injection, until $10 \mathrm{~min}$ had elapsed and thereafter at $20,30,40$, and $60 \mathrm{~min}$ after the glucose injection. The glucose tolerance was assessed as the rate of disappearance of glucose from the blood, measured as the slope of the glucose curve plotted on semilogarithmic paper against time $\left(K=\left(\ln 2 / \mathrm{t} \frac{1}{2}\right) \times 100\right)$. A $K$ value for the fall of serum free fatty acids during the i.v. glucose tolerance test was calculated in the same way.

Blood glucose, serum insulin, and FFA in serum were measured in each of the above-mentioned samples, including two samples obtained shortly after the patients' admission to hospital, as well as two samples obtained after overnight fasting, just before the injection of glucose. Plasma noradrenaline and plasma adrenaline were measured after admission (two samples), after overnight fasting (two samples), and 10,30 , and $60 \mathrm{~min}$ after i.v. injection of glucose.

The normal subjects were studied after overnight fasting. Blood samples were obtained before and after intravenous injection of $25 \mathrm{~g}$ of glucose, as described for the patients with AMI.

To study the influence of the blood sampling site on the plasma catecholamine concentration, blood was also collected from the brachial artery in one patient with AMI. Blood samples were collected from various sites in one normal subject in whom high plasma catecholamine levels had been induced by strenuous exercise.

An informed consent to the procedure was obtained from all subjects studied.

Conventional probability levels of significance were used in the statistical analysis, and a $P$ value greater than 0.05 was considered nonsignificant. The $t$ test was used for testing the significance of differences between mean values. Regression analysis was performed according to Bailey (15).

Analyses. Plasma noradrenaline and plasma adrenaline were measured by the double-isotope derivative technique described by Engelman and Portnoy (11), except for some minor modifications. Results of recovery experiments and other methodological data have been presented elsewhere (13). Approximately $4-5 \mathrm{ml}$ of plasma was used in each analysis.

Glucose concentration in whole blood was measured by a glucose oxidase method (16). FFA in serum were measured by a modification of Dole's titrimetric method (17). Plasma insulin was measured by wick chromatography (18).

\section{RESULTS}

Pertinent clinical data in the 10 patients with AMI and in the normal subjects are given in Table I. Mean values of the measured parameters are given in Table II. Pertinent laboratory data in each individual patient with AMI are given in Table III. In the individual patient, the plasma noradrenaline and adrenaline concentrations were very similar at admission to hospital, after fasting, and during the intravenous glucose tolerance test. The five mean values did not differ significantly from each other. The mean noradrenaline and adrenaline concentration during the glucose tolerance test was calculated for each person and used for further analysis $(\mathrm{Na}$ $\mathrm{Gt}$ ). The mean plasma catecholamine concentration varied considerably among the different patients and correlated with their degree of illness ( $P$ less than 0.05 ). The mean plasma noradrenaline and adrenaline concentration was significantly higher in patients with AMI than in the five normal subjects ( $P$ less than $0.02,0.001$ ). The catecholamine values were also higher than those obtained in a group of patients admitted to the coronary care unit with chest pain but without evidence of cardiovascular disease (1) ( $P$ less than 0.02 ). 7 of the 10 patients with AMI had mean plasma noradrenaline values exceeding the calculated upper $95 \%$ limit of the values obtained in the controls. The plasma adrenaline concentration was not correlated with the plasma noradrenaline concentration. Furthermore plasma adrenaline was not 
TABLE I

Pertinent Clinical Data in the Patients with AMI and in the Control Subjects

\begin{tabular}{|c|c|c|c|c|}
\hline No & Age & Sex & $\begin{array}{l}\text { Ideal } \\
\text { body } \\
\text { weight }\end{array}$ & $\begin{array}{l}\text { Coronary } \\
\text { prognostic } \\
\text { index }\end{array}$ \\
\hline \multicolumn{5}{|c|}{ Patients with AMI } \\
\hline 1 & 57 & M & 117 & 7.3 \\
\hline 2 & 56 & $\mathrm{M}$ & 110 & 5.7 \\
\hline 3 & 73 & $\mathrm{~F}$ & 105 & 6.1 \\
\hline 4 & 67 & $\mathrm{~F}$ & 111 & 6.5 \\
\hline 5 & 48 & M & 101 & 2.6 \\
\hline 6 & 65 & $\mathrm{M}$ & 92 & 11.4 \\
\hline 7 & 71 & $\mathrm{M}$ & 106 & 14.5 \\
\hline 8 & 66 & $\mathrm{~F}$ & 94 & 5.1 \\
\hline 9 & 67 & $\mathrm{M}$ & 105 & 8.8 \\
\hline 10 & 44 & $\mathrm{M}$ & 112 & 5.9 \\
\hline Mean & 61 . & & 105 & 7.4 \\
\hline \multicolumn{5}{|c|}{ Control Subjects } \\
\hline 1 & 51 & $\mathrm{M}$ & 106 & \\
\hline 2 & 65 & $\mathrm{~F}$ & 105 & \\
\hline $\begin{array}{l}3 \\
4\end{array}$ & $\begin{array}{l}53 \\
58\end{array}$ & $\begin{array}{l}M \\
M\end{array}$ & $\begin{array}{l}90 \\
89\end{array}$ & \\
\hline 5 & 68 & $\mathrm{~F}$ & 123 & \\
\hline Mean & 59 & & 103 & \\
\hline
\end{tabular}

correlated with any of the metabolic parameters mentioned below and will not be considered in detail in the following. However, a correlation was observed between the adrenaline concentration during fasting and after intravenous injection of glucose in the individual patients with AMI ( $P$ less than 0.05).

Blood glucose concentrations are given in Table II and III. There was a highly significant correlation between the fasting glucose concentration and plasma noradrenaline after overnight fast $(\mathrm{Na}-\mathrm{Fa})$ in patients with AMI ( $P$ less than 0.001 , Fig. 1 ). In one patient a blood sample was not available for estimation of the fasting glucose concentration. The mean fasting glucose concentration in patients with AMI and elevated plasma noradrenaline was significantly higher than in the control subjects ( $P$ less than 0.01 ).

The glucose $K$ value varied between 2.04 and 0.64 in patients with AMI. There was a significant correlation between the $\log K$ value and plasma Na-Gt ( $P$ less than 0.01 , Fig. 2). The mean $K$ value in patients with AMI and elevated plasma noradrenaline was significantly lower than the $K$ value in the controls ( $P$ less than $0.05)$.

Plasma insulin concentrations in the fasting state averaged $18 \mu \mathrm{U} / \mathrm{ml}$ in patients with AMI. This value was significantly higher than the mean value obtained in the normal subjects ( $P$ less than 0.05$)$. Fasting insulin concentrations were correlated neither with the $\mathrm{Na}-\mathrm{Fa}$ concentration nor with fasting glucose concentration. Similar negative results were obtained when the admission values were analyzed. Fasting insulin values were not correlated to ideal body weight. The rise in plasma insulin during the glucose tolerance test varied considerably in the individual patients. Patients with an initial high response tended to decline rapidly towards basal values, while patients with an initial low response exhibited a continuous rise during the test. In most patients the level was rather constant between 4 and 10 min. We have therefore used the mean of the 4-10 min values for further analysis. The rise in insulin during the glucose tolerance test was dependent on the fasting insulin concentration $(P=0.05, r=0.63)$. We have therefore calculated an insulin index as the ratio: mean rise in insulin at $4-10 \mathrm{~min} /$ fasting insulin values.

There was a strong correlation between the glucose $\mathrm{K}$ value and the insulin index ( $P$ less than 0.001 , Fig. 3 ) and between $\log$ insulin index and the plasma $\mathrm{Na}-\mathrm{Gt}$ $(P$ less than 0.005 , Fig. 4$)$. Significant results were also obtained when the absolute insulin values were used in the statistical analysis; however, the level of significance was much lower ( $P$ less than 0.05 ).

Multiple regression analysis was carried out with the $\log K$ value as the dependent variable and the $\log$ insulin index and the plasma $\mathrm{Na}-\mathrm{Gt}$ concentration as the two independent variables. This analysis showed that the statistical effect of the insulin index and plasma $\mathrm{Na}-\mathrm{Gt}$ on the $K$ value could not be separated from each other and both became insignificant. This means that in the individual patient with AMI a low glucose $K$ value was combined with a low insulin index and a high plasma noradrenaline concentration. A high $K$ value was combined with a high insulin index and a low plasma noradrenaline level.

The mean rise in insulin in patients with AMI and elevated plasma noradrenaline was $20 \mu \mathrm{U} / \mathrm{ml}$ and the corresponding value in the controls $46 \mu \mathrm{U} / \mathrm{ml}$ ( $P$ less than 0.05). The mean insulin index in patients with AMI and elevated plasma noradrenaline was 1.1 , significantly lower than the corresponding value of 3.9 in the controls ( $P$ less than 0.01 ).

The concentration of FFA in serum is given in Table II and III. The mean fasting values in patients with AMI and elevated plasma noradrenaline were significantly higher than in the controls ( $P$ less than 0.05 ). Fasting FFA in patients with AMI was not correlated to fasting insulin concentrations or to plasma Na-Fa. A highly significant negative correlation obtained between FFA values on admission and plasma insulin on admission ( $P$ less than 0.01 ) but not with plasma noradrenaline at admission to hospital ( $\mathrm{Na}-\mathrm{Ad}$ ). Inspection of the data obtained in the fasting state suggested that there 
TABLE II

Mean Values of Plasma Noradrenaline, Plasma Adrenaline, Blood Glucose, Serum Insulin, FFA in Serum, Glucose $K$ Value, FFA $K$ Value and Insulin Index (II) in 10 Patients with AMI and in Five Control Subjects

\begin{tabular}{|c|c|c|c|c|c|c|c|c|c|c|c|c|}
\hline & \multirow[b]{2}{*}{ Admission } & \multirow[b]{2}{*}{ Fasting } & \multicolumn{9}{|c|}{ Glucose tolerance test, $\min$} & \multirow[b]{2}{*}{$\mathrm{K}$ or II } \\
\hline & & & 2 & 4 & 6 & 8 & 10 & 20 & 30 & 40 & 60 & \\
\hline \multicolumn{13}{|c|}{ Plasma noradrenaline, $n g / m l$} \\
\hline AMI patients & 1.03 & 0.97 & & & & & 0.89 & & 0.88 & & 1.00 & \\
\hline $\mathrm{SD}$ & 0.65 & 0.54 & & & & & 0.51 & & 0.61 & & 0.57 & \\
\hline Controls & & 0.43 & & & & & 0.43 & & 0.39 & & 0.40 & \\
\hline $\mathrm{SD}$ & & 0.10 & - & & & & 0.15 & & 0.13 & & 0.11 & \\
\hline \multicolumn{13}{|c|}{ Plasma adrenaline, $n g / m l$} \\
\hline AMI patients & 0.17 & 0.12 & & & & & 0.10 & & 0.13 & & 0.11 & \\
\hline $\mathrm{SD}$ & 0.09 & 0.05 & & & & & 0.04 & & 0.06 & & 0.05 & \\
\hline Controls & & 0.05 & & & & & 0.04 & & 0.04 & & 0.04 & \\
\hline $\mathrm{SD}$ & & 0.02 & & & & & 0.02 & & 0.01 & & 0.02 & \\
\hline \multicolumn{13}{|c|}{ Blood glucose, $\mathrm{mg} / 100 \mathrm{ml}$} \\
\hline AMI patients & 108 & 101 & 271 & 378 & 326 & 268 & 247 & 217 & 189 & 178 & 153 & 1.15 \\
\hline $\mathrm{SD}$ & 25 & 20 & 171 & 209 & 155 & 25 & 26 & 39 & 36 & 42 & 43 & 0.53 \\
\hline Controls & & 73 & 340 & 380 & 266 & 252 & 235 & 197 & 175 & 156 & 127 & 1.51 \\
\hline $\mathrm{SD}$ & & 2 & 178 & 159 & 42 & 25 & 14 & 18 & 24 & 32 & 33 & 0.54 \\
\hline \multicolumn{13}{|c|}{ Serum insulin, $\mu U / m l$} \\
\hline AMI patients & 2.3 & 18 & 23 & 54 & 54 & 55 & 50 & 41 & 42 & 38 & 36 & 1.7 \\
\hline $\mathrm{SD}$ & 12 & 7 & 15 & 52 & 47 & 51 & 46 & 18 & 18 & 15 & 17 & 1.5 \\
\hline Controls & & 12 & 62 & 69 & 63 & 51 & 53 & 42 & 39 & 37 & 31 & 3.9 \\
\hline SD & & 2 & 20 & 23 & 16 & 14 & 17 & 14 & 11 & 9 & 11 & 1.6 \\
\hline \multicolumn{13}{|c|}{ FFA in serum, meq/liter } \\
\hline AMI patients & 0.780 & 0.818 & 0.775 & 0.777 & 0.755 & 0.674 & 0.750 & 0.605 & 0.479 & 0.431 & 0.390 & 2.6 \\
\hline SD & 0.290 & 0.286 & 0.287 & 0.255 & 0.244 & 0.179 & 0.233 & 0.293 & 0.238 & 0.293 & 0.208 & 1.0 \\
\hline Controls & & 0.511 & 0.568 & 0.530 & 0.506 & 0.452 & 0.458 & 0.338 & 0.210 & 0.182 & 0.138 & 3.8 \\
\hline SD & & 0.240 & 0.227 & 0.245 & 0.210 & 0.276 & 0.268 & 0.214 & 0.144 & 0.167 & 0.131 & 0.7 \\
\hline
\end{tabular}

was a negative correlation between FFA and plasma insulin and a positive correlation between FFA and plasma $\mathrm{Na}-\mathrm{Fa}$. Multiple regression analysis was carried out with the $\log$ fasting FFA values as the dependent vari- able and the fasting insulin concentration and plasma $\mathrm{Na}-\mathrm{Fa}$ as the two independent variables. As mentioned above, fasting insulin concentrations and plasma $\mathrm{Na}-\mathrm{Fa}$ were not correlated to each other. The partial regression

TABLE III

Pertinent Laboratory Data in Individual Patients with AMI

\begin{tabular}{|c|c|c|c|c|c|c|c|c|c|c|c|c|c|c|c|c|}
\hline \multirow[b]{3}{*}{ No } & \multirow{2}{*}{\multicolumn{6}{|c|}{ Plasma }} & \multicolumn{6}{|c|}{ Serum } & \multirow[b]{3}{*}{$\begin{array}{l}\text { Insulin } \\
\text { index }\end{array}$} & \multirow{2}{*}{\multicolumn{2}{|c|}{ Serum }} & \multirow[b]{3}{*}{$\begin{array}{c}\text { FFA } \\
\text { K value }\end{array}$} \\
\hline & & & & & & & \multirow{2}{*}{\multicolumn{3}{|c|}{$\begin{array}{ccc}\text { Glucose } & \text { Glucose } & \text { Glucose } \\
\text { (Ad) } & (\mathrm{Fa}) & \mathrm{K} \text { value }\end{array}$}} & \multirow[b]{2}{*}{$\begin{array}{l}\text { Insulin } \\
\text { (Ad) }\end{array}$} & \multirow[b]{2}{*}{$\begin{array}{l}\text { Insulin } \\
(\mathrm{Fa})\end{array}$} & \multirow{2}{*}{$\begin{array}{c}\text { Increase } \\
\text { in } \\
\text { insulin } \\
4-10 \\
\text { min }\end{array}$} & & & & \\
\hline & Na-Ad & A-Ad & $\mathrm{Na}-\mathrm{Fa}$ & $\mathrm{A}-\mathrm{Fa}$ & $\mathrm{Na}-\mathrm{Gt}$ & $\mathrm{A}-\mathrm{Gt}$ & & & & & & & & $\begin{array}{l}\text { FFA } \\
\text { (Ad) }\end{array}$ & $\begin{array}{l}\text { FFA } \\
(\mathrm{Fa})\end{array}$ & \\
\hline & & \multicolumn{4}{|c|}{$n g / m l$} & \multicolumn{4}{|c|}{$\mathrm{mg} / 100 \mathrm{ml}$} & \multicolumn{3}{|c|}{$\mu U / m l$} & \multicolumn{4}{|c|}{ meq/liter } \\
\hline 1 & 1.02 & 0.07 & 0.99 & 0.10 & 0.95 & 0.12 & 93 & - & 1.19 & 33 & 19 & 39 & 2.1 & 0.657 & 0.718 & 2.1 \\
\hline 2 & 0.89 & 0.22 & 0.73 & 0.21 & 0.78 & 0.21 & 100 & 107 & 0.69 & 13 & 18 & 21 & 1.2 & 0.648 & 0.712 & 2.0 \\
\hline 3 & 0.30 & 0.09 & 0.27 & 0.08 & 0.26 & 0.08 & 104 & 78 & 2.03 & 36 & 30 & 147 & 4.9 & 0.452 & 0.445 & 3.7 \\
\hline 4 & 0.53 & 0.21 & 0.68 & 0.15 & 0.63 & 0.12 & 99 & 92 & 1.28 & 23 & 16 & 19 & 1.2 & 0.906 & 1.028 & 3.5 \\
\hline 5 & 0.31 & 0.07 & 0.43 & 0.03 & 0.39 & 0.06 & 103 & 77 & 2.04 & 38 & 13 & 39 & 3.0 & 0.371 & 0.497 & 4.3 \\
\hline 6 & - & - & 1.00 & 0.11 & 1.08 & 0.17 & - & 107 & 0.81 & 8 & 10 & 2 & 0.2 & 1.315 & 1.333 & 1.2 \\
\hline 7 & 2.28 & 0.32 & 2.20 & 0.16 & 2.03 & 0.12 & 166 & 140 & 0.64 & 13 & 24 & 4 & 0.2 & 0.909 & 1.105 & 1.6 \\
\hline 8 & 1.24 & $0: 11$ & 1.13 & 0.12 & 1.06 & 0.08 & 95 & 97 & 0.81 & 8 & 8 & 9 & 1.1 & 1.130 & 1.002 & 2.0 \\
\hline 9 & 0.99 & 0.29 & 0.90 & 0.11 & 0.72 & 0.08 & 83 & 90 & 1.31 & 27 & 23 & 57 & 2.5 & 0.705 & 0.719 & 3.1 \\
\hline 10 & 1.71 & 0.14 & 1.37 & 0.13 & 1.34 & 0.08 & 127 & 119 & 0.71 & 30 & 23 & 10 & 0.4 & 0.710 & 0.623 & 2.5 \\
\hline
\end{tabular}

Ad, admission; Fa, fasting; Gt, glucose tolerance test; Na, plasma noradrenaline; A, plasma adrenaline. 


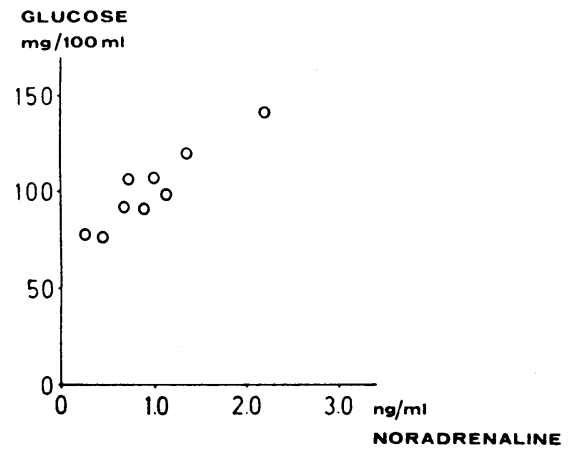

FIGURE 1 Fasting blood glucose concentration in patients with AMI plotted on the ordinate vs. fasting plasma noradrenaline concentration. $P$ less than 0.001 .

coefficients were significant ( $P$ less than 0.05 in both cases).

The equation of the regression line is:

$z(\log$ FFA $\mu$ eq $/$ liter $)=\frac{-0.0123(\text { insulin } \mu \mathrm{U} / \mathrm{ml})+}{0.1727(\mathrm{Na}-\mathrm{Fa} \mathrm{ng} / \mathrm{ml})+2.947}$

The rate of fall in FFA in serum after intravenous injection of glucose was expressed like the glucose $K$ value. The FFA $K$ value was correlated with the insulin index ( $P$ less than 0.05, Fig. 5) and with the plasma Na-Gt ( $P$ less than 0.05 , Fig. 6 ). By multiple regression analysis with the FFA $K$ value as the dependent variable and the insulin index and the plasma $\mathrm{Na}-\mathrm{Gt}$ as the two independent variables, both partial regression coefficients became insignificant, indicating that a low $K$ value, a low insulin index, and a high plasma $\mathrm{Na}-\mathrm{Gt}$ were combined in the individual patient, and vice versa. The mean FFA $K$ value was 2.1 in the patients with elevated plasma noradrenaline, significantly lower than

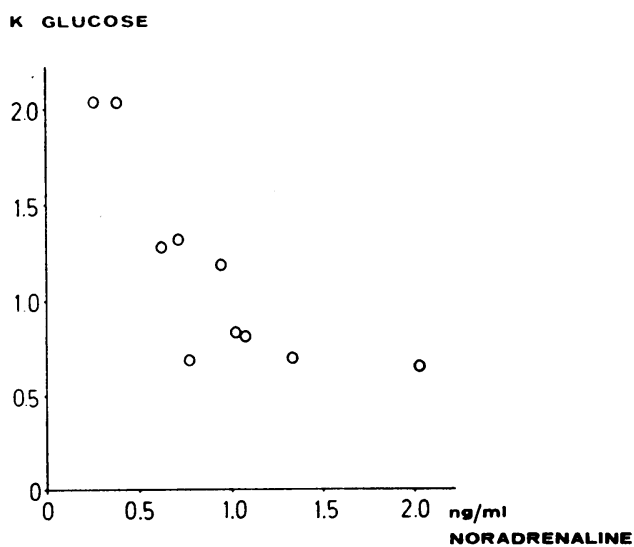

FIGURE 2 Glucose tolerance in patients with AMI expressed as the $K$ value and plotted on the ordinate vs. plasma noradrenaline concentration during the intravenous glucose tolerance test. $P$ less than 0.01 .

\section{N. J. Christensen and J. Videbaek}

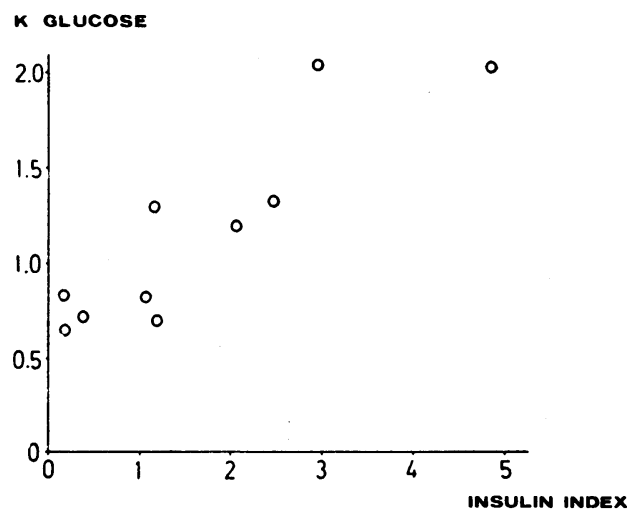

FIgURE 3 Glucose tolerance in patients with AMI expressed as the $K$ value and plotted on the ordinate vs. insulin index (mean rise in insulin $[\mu \mathrm{U} / \mathrm{ml}]$ 4-10 min after i.v. injection of glucose/fasting insulin $[\mu \mathrm{U} / \mathrm{ml}]) . P$ less than 0.001 .

the corresponding value of 3.8 in the control subjects ( $P$ less than 0.01 ).

Unfortunately only 4 of the 10 patients with AMI could be re-examined. The data are given in Table IV. Mean fasting insulin concentration was approximately halved at the second examination, but the difference was not significant. In two of the patients, 3 and 5 , the other parameters were rather unchanged. Both of these subjects had normal plasma catecholamine concentrations during AMI. In the two other subjects, 8 and 10, with high noradrenaline values at the initial examination the rise in insulin after intravenous glucose was doubled, the insulin index increased, the glucose $K$ value improved and the fasting glucose concentration lower at the second examination. Plasma noradrenaline concentration was now normal for their age. The improvement in glu-

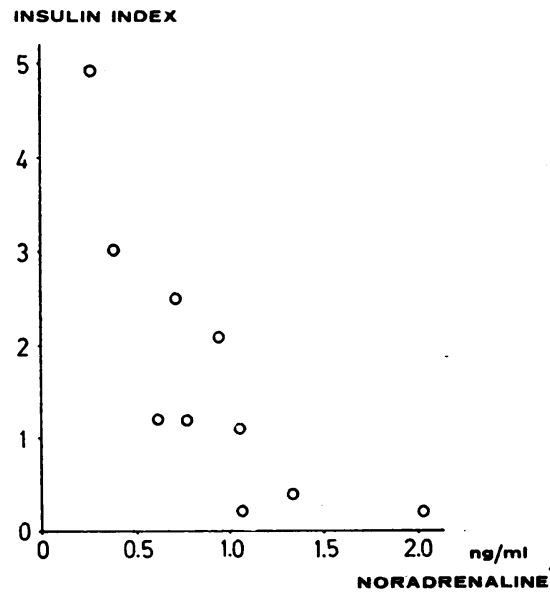

FIGURE 4 Insulin index in patients with AMI plotted on the ordinate vs. plasma noradrenaline concentration during the i.v. glucose tolerance test. $P$ less than 0.005 . 


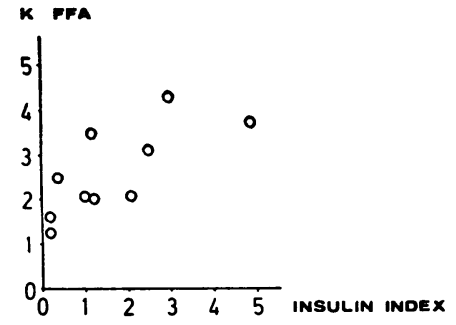

FIGURE 5 Rate of fall of free fatty acids in serum after i.v. injection of glucose in patients with AMI expressed as the $K$ value and plotted on the ordinate vs. insulin index. $P$ less than 0.05 .

cose tolerance in patients 8 and 10 was not larger than could be expected from the rise in the insulin index (Fig. 3).

Table $\mathrm{V}$ shows values of noradrenaline and adrenaline in plasma obtained from various sites in a normal subject during exercise and in a patient with AMI. In both subjects the two sets of samples were obtained at a short interval. It appears that the values are approximately similar on the arterial and venous side.

\section{DISCUSSION}

Patients with AMI show a transitory hyperglycemia. There are, however, conflicting data about the duration of the hyperglycemia (3-6). Lebovitz, Schultz, Matthews, and Scheele (4) observed an initial depression of glucose tolerance but only in patients examined within $48 \mathrm{~h}$ after admission to hospital. There was no further improvement when results obtained from 6 to 14 days and after 18 days were compared. No change in glucose

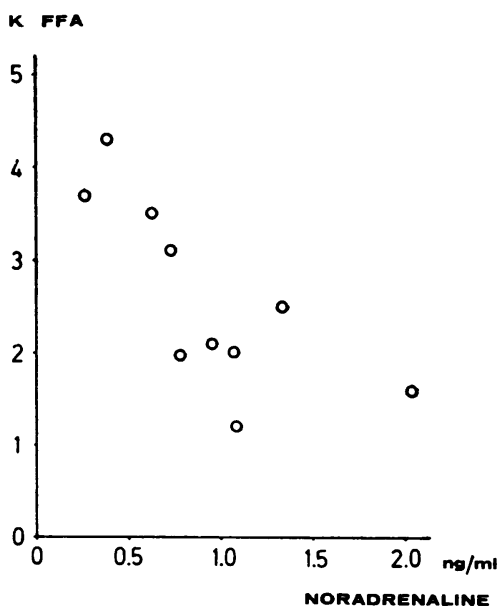

FIGURE 6 Rate of fall of free fatty acids after i.v. injection of glucose in patients with AMI expressed as the $K$ value and plotted on the ordinate vs. plasma noradrenaline concentration during the i.v. glucose tolerance test. $P$. less than 0.05 . tolerance was observed in a small group of patients examined between 48 and $96 \mathrm{~h}$ after admission to hospital as compared to a later examination. In addition to the initial hyperglycemia, patients with AMI exhibit raised FFA $(5,8,9)$. The rise in serum insulin in response to intravenous glucose or to tolbutamide has been found to be reduced, especially in patients with complications $(5,10)$, while Lebovitz et al. (4) were more impressed by a hyperinsulinemic response occurring between the 6 th and 14th day.

Fasting growth hormone concentration has been found to be normal $(4,19)$ but an early rise after glucose administration has been observed. Plasma cortisol is elevated especially in patients with complications (20-24). Plasma glucagon has also been found to be elevated (25).

The initial metabolic alterations in patients with AMI have been related to an increased adrenergic activity, especially an increased adrenaline secretion (4, 5, 10, 26). Oliver (26) considered the rise in FFA to be due to an increased noradrenaline secretion and a relationship between FFA and plasma noradrenaline has been reported $(27,28)$.

The present study indicates, however, that elevated plasma adrenaline concentrations were not the cause of the altered metabolic state in patients with AMI. Plasma adrenaline did not correlate with any of the measured metabolic parameters.

Highly significant correlations were observed between plasma noradrenaline and the fasting glucose concentration, the glucose tolerance, and the insulin index and a weaker but significant correlation was obtained with the rate of fall of FFA after i.v. injection of glucose. $\mathrm{Na}-\mathrm{Fa}$ was correlated to fasting FFA only after the varying insulin levels had been taken into account.

TABLE IV

Results Obtained in Four Patients with AMI

Reexamined 3 Mo. Later

\begin{tabular}{|c|c|c|c|c|c|}
\hline No & $\begin{array}{l}\text { Fasting } \\
\text { insulin }\end{array}$ & $\begin{array}{l}\text { Insulin } \\
\text { index }\end{array}$ & $\begin{array}{l}\text { Glucose } \\
\mathrm{K} \text { value }\end{array}$ & $\begin{array}{c}\text { Plasma } \\
\mathrm{Na}\end{array}$ & $\begin{array}{l}\text { Fasting } \\
\text { glucose }\end{array}$ \\
\hline & $\mu U / m l$ & & & $n g / m l$ & $\mathrm{mg} / 100 \mathrm{~m}$ \\
\hline $3 a$ & 30 & 4.9 & 2.03 & 0.28 & 78 \\
\hline b & 8 & 6.0 & 1.73 & 0.41 & 76 \\
\hline $5 a$ & 13 & 3.0 & 2.04 & 0.38 & 77 \\
\hline b & 9 & 5.4 & 2.20 & 0.39 & 79 \\
\hline $8 a$ & 8 & 1.1 & 0.81 & 1.14 & 97 \\
\hline b & 8 & 2.3 & 1.58 & 0.47 & 66 \\
\hline $10 \mathrm{a}$ & 23 & 0.4 & 0.71 & 1.47 & 119 \\
\hline b & 8 & 2.6 & 1.41 & 0.32 & 84 \\
\hline
\end{tabular}

a, admission with AMI; b, 3 mo later. 
TABLE V

Effect of the Sampling Site on Plasma Noradrenaline and Plasma Adrenaline Concentration

\begin{tabular}{|c|c|c|c|c|c|c|c|c|}
\hline & \multicolumn{2}{|c|}{ Brachial artery } & \multicolumn{2}{|c|}{ Pulmonary artery } & \multicolumn{2}{|c|}{ Inferior vena cava } & \multicolumn{2}{|c|}{ Superior vena cava } \\
\hline & $\mathrm{Na}$ & $\mathbf{A}$ & $\mathrm{Na}$ & $\mathbf{A}$ & $\mathrm{Na}$ & $\mathbf{A}$ & $\mathrm{Na}$ & $\mathbf{A}$ \\
\hline & \multicolumn{2}{|c|}{-} & \multicolumn{4}{|c|}{$n g / m l$} & & \\
\hline \multirow{2}{*}{ Normal subject } & 1.57 & 0.51 & 1.57 & 0.57 & 1.65 & 0.62 & 1.83 & 0.40 \\
\hline & 2.14 & 0.58 & 1.76 & 0.50 & 1.84 & 0.66 & 2.26 & 0.55 \\
\hline \multirow[t]{2}{*}{ Patient 9 with AMI } & 0.79 & 一 & & & & & 0.72 & - \\
\hline & 0.90 & 0.11 & & - & & & 0.83 & 0.10 \\
\hline
\end{tabular}

The important question is whether the observed statistical correlations between plasma noradrenaline and the other metabolic parameters indicate a causal relationship. Both factors (e.g., plasma noradrenaline and the insulin index) could simply reflect different degrees of severity of the disease in the individual patients, rather than being causally related to each other. The metabolic and circulatory situation in patients with AMI is so complicated that plasma noradrenaline cannot be interpreted in terms of sympathetic nervous activity in different organs, or be divided into a metabolic and circulatory component. It appears, however, that the plasma noradrenaline concentration is so high in many patients with AMI that a major metabolic effect may well occur as a result of the circulatory noradrenaline per se. The highest plasma noradrenaline concentration observed in the present study was just above $2 \mathrm{ng} / \mathrm{ml}$. According to Cohen, Holland, Sha, and Goldenberg (29), this corresponds to an infusion rate of noradrenaline in adults of approximately $12 \mu \mathrm{g} / \mathrm{min}$.

Porte and Williams (30) infused $6 \mu \mathrm{g}$ noradrenaline/ min i.v. to normal subjects and observed a considerable decrease in the plasma insulin response to i.v. glucose infusion. FFA in plasma rose while glucose infusion alone was accompanied by a decrease in FFA concentration, as expected. Fasting insulin concentration remained unchanged. Ettinger, Oldewurtel, Weisse and Regan (31) infused $0.1 \mu \mathrm{g} / \mathrm{kg} / \mathrm{min}$ of noradrenaline to four normal subjects during an i.v. glucose tolerance test and observed a significant reduction in the glucose disappearance rate and a diminuation of the rise in plasma insulin. Carlstr $\phi m$ (32) infused noradrenaline i.v. at a rate of $7.5 \mu \mathrm{g} / \mathrm{min}$ to five normal fasting subjects over $10 \mathrm{~min}$. FFA rose from $0.48 \mathrm{meq} / \mathrm{liter}$ to 1.41 $\mathrm{meq} /$ liter. The blood glucose concentration rose from 80 to $100 \mathrm{mg} / 100 \mathrm{ml}$. It is likely, however, that in the experiments performed by Carlstr $\phi_{m}$ (32) the glucose concentration would have been even higher if the noradrenaline had been infused for a longer period of time (33).

It has to be emphasized that the mechanism of the changes appears to be different in the fasting state as compared to the glucose tolerance test. During the glucose tolerance test, the various effects of circulating noradrenaline were probably mediated indirectly via a supression of insulin secretion (decrease in glucose disappearance rate and decline in rate of fall in FFA). In the fasting state, however, noradrenaline was not correlated to serum insulin. There was no evidence in our study that circulating noradrenaline supressed basal insulin secretion. Our data indicate that noradrenaline and fasting insulin exerted independent effects on the level of FFA. There is clearly no simple relationship between plasma noradrenaline and FFA, and it is not possible to predict the FFA concentrations in patients with AMI without knowing the basal insulin concentration. It is well known that lipolysis is extremely sensitive even to small amounts of insulin, and we believe that the negative correlation obtained between fasting serum insulin concentration and FFA indicates that the basal insulin level exerts a considerable control of lipolysis. The variation in fasting insulin level cannot be explained. It is not related to obesity expressed as the ideal body weight (33). It is conceivable, however, that the fasting hyperglycemia partly neutralized an effect of noradrenaline on basal insulin secretion, the correlation between fasting blood glucose concentration and plasma noradrenaline being very close. During the glucose tolerance test there was no correlation between the maximal glucose values obtained after the injection of glucose and plasma noradrenaline (all patients received the same amount of glucose), so that the inhibitory effects of the various plasma noradrenaline levels could be more easily demonstrated.

The significance of other hormones also has to be considered. Plasma cortisol is raised in patients with AMI (20-24), especially in patients with complications, and the level might well be correlated with the plasma noradrenaline concentration. Plasma cortisol was not measured in our patients, and the extent to which plasma cortisol may influence the metabolic situation in patients with AMI seems not to have been elucidated. 
Lebovitz et al (4) observed a hyperinsulinemic response to i.v. glucose in patients with AMI 6-14 days after the patients were admitted to hospital. At a later examination the insulin response was lower but the glucose tolerance unchanged, indicating a period of insulin antagonism occurring between days 6 and 14. In the present study a decreased insulin reponse to glucose, rather than insulin antagonism, characterized the metabolic situation in the initial period after AMI. It is conceivable that insulin antagonism is a milder and therefore often a later-appearing stress phenomenon $(34,35)$. It should be emphasized that the use of the insulin index in the statistical analysis rather than of the absolute insulin values tends to eliminate any effect of insulin antagonism. It is obvious that in the patients with AMI, the insulin index was more reduced than the absolute insulin values.

\section{REFERENCES}

1. Videbaek, J., N. J. Christensen, and B. Sterndorff. 1972. Serial determination of plasma catecholamines in myocardial infarction. Circulation. 46: 846-855.

2. Lukomsky, P. E., and R. G. Oganov. 1972. Blood plasma catecholamines and their urinary excretion in patients with acute myocardial infarction. Am. Heart J. 83: 182-188.

3. Datey, K. K., and N. C. Nanda. 1967. Hyperglycemia after acute myocardial infarction. N. Engl. J. Med. 276: 262-265.

4. Lebovitz, H. E., K. T. Schultz, M. E. Matthews, and R. Scheele. 1969. Acute metabolic responses to myocardial infarction. Changes in glucose utilization and secretion of insulin and growth hormone. Circulation. 39 : 171-181.

5. Allison, S. P., M. J. Chamberlain, and P. Hinton. 1969. Intravenous glucose tolerance, insulin, glucose, and free fatty acid levels after myocardial infarction. Br. Med. J. 4: 776-778.

6. Pearson, D. 1971. Intravenous glucose tolerance in myocardial infarction. Postgrad. Med.J. 47: 648-650.

7. Kurt, T. L., E. Genton, C. Chidsey, P. Beck, and K. E. Sussman. 1973. Carbohydrate metabolism and acute myocardial infarction: circulating glucose, insulin, cortisol and growth hormone responses and excretion of catecholamines. Chest. $64: 21-25$.

8. Kurien, V. A., and M. F. Oliver. 1966. Serum-freefatty-acids after acute myocardial infarction and cerebral vascular occlusion. Lancet. 2: 122-127.

9. Rutenberg, H. L., J. C. Pamintuan, and L. A. Soloff. 1969. Serum-free-fatty-acids and their relation to complications after acute myocardial infarction. Lancet. 2: 559-564.

10. Taylor, S. H., C. Saxton, P. A. Majid, J. R. W. Dykes, P. Ghosh, and J. B. Stoker. 1969. Insulin secretion following myocardial infarction. Lancet. 2: 1373-1377.

11. Engelman, K., and B. Portnoy. 1970. A sensitive double-isotope derivative assay for norepinephrine and epinephrine. Circ. Res. 26: 53-57.
12. Christensen, N. J. 1972. Plasma catecholamines in longterm diabetics with and without neuropathy and in hypophysectomized subjects. J. Clin. Invest. 51: 779787.

13. Christensen, N. J. 1973. Plasma noradrenaline and adrenaline in patients with thyrotoxicosis and myxoedema. Clin. Sci. (Oxf.). 45: 163-171.

14. Norris, R. M., P. W. T. Brandt, D. E. Caughey, A. J. Lee, and P. J. Scott. 1969. A new coronary prognostic index. Lancet. 1: 274-278.

15. Bailey, N. T. J. 1959. Statistical Methods in Biology. English Universities Press Ltd., London. 1st edition. 91-149.

16. Christensen, N. J. 1967. Notes on the glucose oxidase method. Scand. J. Clin. Lab. Invest. 19: 379-384.

17. Trout, D. L., E. H. Estes, Jr., and S. J. Friedberg. 1960. Titration of free fatty acids of plasma: a study of current methods and a new modification. J. Lipid Res. 1: 199-202.

18. Ørskov, H. 1967. Wick-chromatography for the immunoassay of insulin. Scand. J. Clin. Lab. Invest. 20: 297-304.

19. Boden, G. 1971. Hormonal and metabolic disturbances during acute and subacute myocardial infarction in man. Diabetologia. 2 : 240-246.

20. Logan, R. W, and W. R. Murdoch. 1966. Blood-levels of hydrocortisone, transaminases, and cholesterol after myocardial infarction. Lancet. 2: 521-524.

21. Bailey, R. R., M. H. Abernethy, D. W. Beaven. 1967. Adrenocortical response to the stress of an acute myocardial infarction. Lancet. 1 : 970-973.

22. Hansen, B., J. Beck-Nielsen, J. Juul, B. L. Nielsen, and F. U. Nielsen. 1969. Plasma-hydrocortisone values in heart disease. Acta Med. Scand. 186: 411-416.

23. Prakash, R., W. W. Parmley, M. Horvat, and H. J. C. Swan. 1972. Serum cortisol, plasma free fatty acids and urinary catecholamines as indicators of complications in acute myocardial infarction. Circulation. 45: 736-745.

24. Burckhardt, P., J.-P. Felber, and C. Perret. 1972. Adrenocortical, insulin and metabolic changes in response to acute myocardial infarction. Helv. Med. Acta. 36 : 277-293.

25. Laniado, S., P. Segal, and B. Esrig. 1973. The role of glucagon hypersecretion in the pathogenesis of hyperglycemia following acute myocardial infarction. Circulation. 48: 797-800.

26. Oliver, M. F. 1972. Metabolic response during impending myocardial infarction. II. Clinical implications. Circulation. 45 : 491-500.

27. Januszewicz, W., M. Szanjderman, M. Ciswicka-Sznajderman, B. Wocial, and Z. Rymaszewski. 1971. Plasma free fatty acid and catecholamine levels in patients with acute myocardial infarction. Br. Heart J. 33:716 718.

28. Muiesan, G., and C. Valori. 1970. Aritmie cardiache, concentrazioni plasmatiche di acidi grassi non esterificati e attivita' del sistema adrenosimpatico nell' infarto miocardico acuto. Recenti Prog. Med. 49: 536-546.

29. Cohen, G., B. Holland, J. Sha, and M. Goldenberg. 1959. Plasma concentrations of epinephrine and norepinephrine during intravenous infusions in man. $J$. Clin. Invest. 38: 1935-1941.

30. Porte, Jr., D., and R. H. Williams. 1966. Inhibition of insulin release by norepinephrine in man. Science (Wash., D. C.). 152: 1248-1250. 
31. Ettinger, P. O., H. A. Oldewurtel, A. B. Weisse, and T. J. Regan. 1968. Diminished glucose tolerance and immunoreactive insulin response in patients with nonischemic cardiac disease. Circulation. 38: 559-567.

32. Carlstr $\not \mathrm{m}$, S. 1967. Studies on fatty acid metabolism in diabetics during exercise. VI. Infusion of norepinephrine to male, non-insulin-treated juvenile diabetics. Acta Med. Scand. 182: 513-522.

33. Robertson, R. P., and D. Porte, Jr. 1973. Adrenergic modulation of basal insulin secretion in man. Diabetes. 22: $1-8$.

34. Ross, H. I., D. A. Johnston, T. A. Welborn, and A. D. Wright. 1966. Effect of abdominal operation on glucose tolerance and serum levels of insulin, growth hormone and hydrocortisone. Lancet. 2: 563-566.

35. Allison, S. P., P. Hinton, and M. J. Chamberlain. 1968. Intravenous glucose-tolerance, insulin and freefatty-acid levels in burned patients. Lancet. 2: 11131116. 